\title{
Reconstruction of internal gravity wave parameters from radio occultation retrievals of vertical temperature profiles in the Earth's atmosphere
}

\author{
V. N. Gubenko, A. G. Pavelyev, R. R. Salimzyanov, and A. A. Pavelyev \\ Kotelnikov Institute of Radio Engineering and Electronics of the Russian Academy of Sciences, Fryazino, \\ Moscow region, Russia
}

Received: 20 January 2011 - Published in Atmos. Meas. Tech. Discuss.: 1 March 2011

Revised: 19 September 2011 - Accepted: 6 October 2011 - Published: 14 October 2011

\begin{abstract}
A new method for the reconstruction of internal gravity wave (IGW) parameters from a single vertical temperature profile measurement in the Earth's atmosphere has been developed. This method does not require any additional information not contained in the profile and may be used for the analysis of profiles measured by various techniques. The criterion for the IGW identification has been formulated and argued. In the case when this criterion is satisfied, then analyzed temperature fluctuations can be considered as wave-induced. The method is based on the analysis of relative amplitude thresholds of the temperature wave field and on the linear IGW saturation theory in which amplitude thresholds are restricted by dynamical (shear) instability processes in the atmosphere. When the amplitude of an internal gravity wave reaches the shear instability limit, energy is assumed to be dissipated in such a way that the amplitude is maintained at the instability limit as the wave propagates upwards. In order to approbate the method we have used data of simultaneous high-resolution balloon measurements of the temperature and wind velocity in the Earth's stratosphere over France where a long-period inertia-gravity wave has been detected. Using the radiosonde temperature data only, we have reconstructed all wave parameters, which were determined by radiosondes, with relative deviations not larger than $30 \%$. An application of the method to the radio occultation (RO) data has given the possibility to identify the IGWs in the Earth's stratosphere and to determine the magnitudes of key wave parameters such as the intrinsic frequency,
\end{abstract}

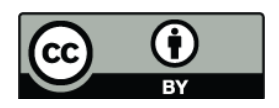

Correspondence to: V. N. Gubenko (vngubenko@gmail.com) amplitudes of vertical and horizontal perturbations of the wind velocity, vertical and horizontal wavelengths, intrinsic vertical and horizontal phase (and group) speeds, kinetic and potential energy, vertical fluxes of the wave energy and horizontal momentum. The obtained results of internal wave studies in the Earth's stratosphere deduced from the COSMIC and CHAMP GPS occultation temperature profiles are presented and discussed.

\section{Introduction}

Internal gravity waves are small scale waves with the restoring force of buoyancy. They had been examined mostly from a theoretical point of view and treated as "noise" for weather prediction for a long time. However, it was suggested by theoretical works in 1980s that upward momentum transport by internal gravity waves is a key process to determine the dynamical structure of the middle atmosphere in the height region of $10-100 \mathrm{~km}$ such as weak wind layers around the mesopause (Lindzen, 1981; Matsuno, 1982) and in the lower stratosphere in the middle latitude region (Tanaka and Yamanaka, 1985). With the aid of MST radars and radiosondes with high vertical resolution developed in the same time period, this theoretical suggestion was confirmed observationally (Tsuda et al., 1990; Sato, 1994). Then, it was further revealed that the role of IGWs is more important than expected theoretically, namely, in the summer stratosphere (Alexander and Rosenlof, 1996), in the equatorial stratosphere (Sato and Dunkerton, 1997; Dunkerton, 1997) and mesosphere (Mayr et al., 1997). Short and mesoscale IGWs contribute largely to the momentum balance of the stratosphere and

Published by Copernicus Publications on behalf of the European Geosciences Union. 
dominate in the mesosphere. In addition, the quasi-biennial and semiannual oscillations in equatorial zonal winds are at least partially driven by the convergence of momentum flux (MF) carried by IGWs (Dunkerton, 1997; Garcia and Sassi, 1999; Mayr et al., 1998; Scaife et al., 2000; Giorgetta et al., 2002). However, the IGW parameterization schemes used in global circulation models are still based on important simplifying assumptions (Hines, 1997; Warner and McIntyre, 1999; Medvedev and Klaassen, 2000) and have a number of freely adjustable parameters. Estimates of the MF still rely more on models than on measurements. Therefore an experimental validation of the IGW MF calculated by models is an important issue.

Recently an increasing number of satellite instruments have appeared for investigation of IGWs. IGW climatologies based on zonal mean values have been published for the Limb Infrared Monitor of the Stratosphere (LIMS) (Fetzer and Gille, 1994). Climatologies were also made for the Microwave Limb Sounder (MLS) on board the Upper Atmosphere Research Satellite (UARS) (Wu and Waters, 1996a, b; McLandress et al., 2000; Wu, 2001), the meteorological program of the Global Positioning System (GPS/MET) (Tsuda et al., 2000), and the Cryogenic Infrared Spectrometers and Telescopes for the Atmosphere (CRISTA) (Preusse et al., 1999, 2000, 2002). These climatologies are all based on gravity wave temperature variances and, in most cases, give estimates of either horizontal or vertical wavelengths. The direct deduction of momentum flux requires the simultaneous measurement of horizontal and vertical wind. Only a very few of measurement techniques are capable of this. Using the dispersion and polarization relations of IGWs, Ern et al. (2004) have shown that the momentum flux can be estimated from the temperature amplitude of the wave field if the horizontal and vertical wavelengths of the waves are known. They used adjacent vertical temperature profiles measured by the CRISTA instrument to estimate the horizontal wavelength of IGWs by an examination of phase variations between profiles. An updated methodology for this type of analysis has been used by Wang and Alexander (2010) to analyze the closely spaced vertical temperature profiles from COSMIC GPS RO observations. Using the large number of combined COSMIC GPS RO temperature soundings, Wang and Alexander (2010) showed estimates of IGW temperature amplitudes, vertical and horizontal wavelengths, intrinsic frequency, and vertical flux of horizontal momentum in the altitude range of 17.5-22.5 km during December 2006 to February 2007. McDonald et al. (2010) have utilized the geographic variation of the RMS temperature difference between pairs of COSMIC GPS RO vertical temperature profiles to derive the horizontal wave number power spectra and IGW characteristics.

There is one general difficulty inherent to all measurements of IGWs. Measured is a state variable of the atmosphere, as for instance wind or temperature, and one has to determine from this measurement which part of the "signal" is attributed to IGWs whereas other part of "signal" may be associated with the stable layers or turbulence. The general approach is to isolate smaller scale variations from a slowly varying background and to declare that these perturbations are the signal imprinted by IGWs. If the measurements provide a time-series at a given location, as for instance lidar or radar measurements do, separation can be made due to frequency analyses. Any scale separation approach has of course two problems. First, not all small scale variations in the atmosphere are IGWs and, second, not all IGWs are of small scales. Observed variations can alternatively be connected with internal gravity waves, turbulence or stable layers. For the correct interpretation of scientific results it is necessary to have an IGW identification criterion, and in the case when this criterion is satisfied, then analyzed variations can be considered as wave-induced. Spectral characterization of the IGW field almost always gives the impression that the wave field is composed of many components at various scales, however, most vertical profiles of velocity or temperature exhibit in any altitude range a single dominant wave structure; the corresponding vertical wave number spectrum typically has $\sim 70 \%$ of the variance within a factor of 2 of the characteristic vertical wave number (Fritts and Alexander, 2003). Additional evidence for a discrete or "narrow spectral", rather than a "broad spectral" description of the local wave filed comes from many studies. Airglow observations more often than not exhibit a single wave structures; balloon, lidar, and rocket data provide evidence of large-scale overturning of apparently individual waves; radar and optical estimates of IGW momentum fluxes provide evidence of discrete (or individual) large amplitude events and such events may comprise a significant part of the mean forcing (Fritts and Alexander, 2003).

Atmospheric observation by satellites with GPS occultation method is powerful to examine the gravity wave distribution around the planet with almost uniform quality. Spectral analysis of the temperature variations found from radio occultation experiments allows for the measurement of the statistical characteristics such as the potential energy of internal waves in the atmosphere (Steiner and Kirchengast, 2000; Tsuda et al., 2000; Tsuda and Hocke, 2002). The advantages of RO observations are that this technique can furnish atmospheric profiles with global spatial coverage and high vertical resolution, and under all weather conditions (Liou et al., 2003 , 2004). It was supposed before that because in radio occultation measurements the observed quantities are only temperature and atmospheric density, it is impossible to estimate IGW parameters such as intrinsic frequency and phase velocities that are necessary to quantify the gravity wave effects. In this context, we have developed a new method for IGW identification and reconstruction of internal gravity wave parameters from the single vertical temperature or density profile measurement in a planetary atmosphere (Gubenko et al., 2008, 2011). 
The aim of this work is the: development and improvement of the method for determination of the intrinsic frequency and other wave parameters from a single vertical temperature profile; verification of the developed technique on the basis of simultaneous balloon measurements of the temperature and wind velocity in the Earth's stratosphere where a saturated internal wave has been detected; demonstration of the practical application of the proposed technique on radio occultation retrievals of temperature profiles in the Earth's atmosphere.

\section{Theoretical relationships}

Following the work of Fritts and Alexander (2003) and Gubenko et al. (2008), let us write the dispersion and polarization relations for an atmosphere in hydrostatic equilibrium. The dispersion relation, assuming $f^{2}<\omega^{2}<<N^{2}$ and $k_{\mathrm{h}}^{2}<<m^{2}$ and $1 /\left(4 H^{2}\right)<<m^{2}$, is given by:

$\frac{\omega^{2}}{k^{2}+l^{2}}=\frac{N^{2}}{m^{2}} \cdot \frac{1}{1-f^{2} / \omega^{2}}$

where $H \simeq 7 \mathrm{~km}$ is the scale height in the middle atmosphere, $N$ is the Brunt-Vaisala, $f$ the inertial, and $\omega$ the intrinsic frequency (frequency observed in the frame moving with the background flow) of the wave. The inertial frequency (Coriolis parameter) $f$ is defined as $f=2 \Omega \cdot \sin \phi$, where $\Omega=7.292 \cdot 10^{-5} \mathrm{rad} \mathrm{s}^{-1}$ is the Earth's rotation rate and $\phi$ is latitude. The parameters $k, l$ and $m$ represent the horizontal and vertical components of the wave vector (wave numbers), $k_{\mathrm{h}}^{2} \equiv k^{2}+l^{2}$ is the horizontal wave vector squared. The sign convention here assumes that $\omega$ is positive definite without losing any generality. The vector $(k, l)$ defines the direction of horizontal propagation. Then $m$ is negative for upward group speed and positive for downward. Thus, for upward $(m<0)$ energy propagation an intrinsic vertical phase speed $\left(C_{\mathrm{pz}}^{\mathrm{in}} \equiv \omega / m\right)$ is downward (Fritts and Alexander, 2003). We can make $l=0$ by taking the $\mathrm{x}$-axis oriented along the direction of the wave propagation.

The polarization relations are given by Gubenko et al. (2008):

$$
\begin{aligned}
& v^{\prime}=-i \cdot \frac{f}{\omega} \cdot u^{\prime}, \\
& w^{\prime}=-\frac{k}{m} \cdot u^{\prime}, \\
& \left|u^{\prime}\right| \approx \frac{g}{N} \cdot \frac{\left|T^{\prime}\right|}{\bar{T}} \cdot\left(1-f^{2} / \omega^{2}\right)^{-1 / 2},
\end{aligned}
$$

where $u$ and $v$ ' are the complex perturbations for the parallel and perpendicular components of wave-induced horizontal wind relative to the wave propagation direction, $w /$ is the complex perturbation for the wave-induced vertical wind. The prime ( $/$ ) and the overbar denote the perturbation and mean quantities, respectively; $g$ is the acceleration due to gravity, $|\widehat{T}|=\left|T^{\prime}\right| / \bar{T}$ is the amplitude of normalized temperature perturbations, and $|u|$ is the amplitude of velocity perturbation in the direction of horizontal wave vector component. Let us consider restrictions of Eqs. (1-4) due to the hydrostatic approximation. With the typical values $H \simeq 7 \mathrm{~km}$ and $N^{2} \approx 4 \cdot 10^{-4} \mathrm{rad}^{2} \mathrm{~s}^{-2}$ in the lower stratosphere, this approximation is appropriate for both low- and medium- frequency IGWs with vertical wavelengths of $\leq 28 \mathrm{~km}$ and with intrinsic frequencies of $\leq 6 \cdot 10^{-3} \mathrm{rad} \mathrm{s}^{-1}$.

Gubenko et al. (2008) proposed a method to identify fluctuations in observed vertical temperature profiles as waveinduced, assuming the IGW shear saturation. They introduced a parameter $a_{\mathrm{e}}$ (relative amplitude threshold) that is defined by:

$a_{\mathrm{e}}=\frac{g|m|}{N^{2}} \cdot \frac{\left|T^{\prime}\right|}{\bar{T}}=\frac{2 \pi \cdot g}{\lambda_{\mathrm{z}} N^{2}} \cdot \frac{\left|T^{\prime}\right|}{\bar{T}}$,

where $\lambda_{z}=2 \pi /|m|$ is the vertical wavelength. The value $a_{\mathrm{e}}$ must be smaller than unity if the fluctuation is due to a saturated monochromatic IGW with respect to shear instability. Gubenko et al. (2008) showed that such important IGW parameters as the intrinsic frequency $(\omega)$, amplitudes of vertical $(|w \prime|)$ and horizontal $(|u /|$ and $|v /|)$ perturbations of the wind velocity, vertical $\left(\lambda_{z}\right)$ and horizontal $\left(\lambda_{h}\right)$ wavelengths, intrinsic vertical $\left(C_{\mathrm{pz}}^{\mathrm{in}}\right)$ and horizontal $\left(C_{\mathrm{ph}}^{\mathrm{in}}\right)$ phase speeds can be derived from observed GPS RO temperature profiles in the case of positive IGW identification.

We wish now to estimate the relative amplitude threshold from the vertical profile of the Brunt-Vaisala frequency squared. We computed the Brunt-Vaisala frequency, $N$, by evaluating (Lindzen, 1981):

$N^{2}=\frac{g}{T} \cdot\left(\frac{\partial T}{\partial z}+\frac{g}{c_{\mathrm{p}}}\right)$,

where $g / c_{\mathrm{p}}=9.8 \cdot 10^{-3} \mathrm{~K} \mathrm{~m}^{-1}$ is the adiabatic temperature lapse rate, $c_{\mathrm{p}}$ is the specific heat capacity at constant pressure. Let us consider an atmosphere with the small waveinduced harmonic perturbations $T^{\prime}(z)$ of the constant basic state temperature field $T_{\mathrm{b}}(z)=\bar{T}(z)$. If $\left|T^{\prime}\right|$ is the wave amplitude $\left(\left|T^{\prime}\right|<<T_{\mathrm{b}}\right)$ and $m$ is the vertical wave number, then the atmospheric temperature $T(z)$ is given by:

$T(z)=T_{\mathrm{b}}(z)+\left|T^{\prime}\right| \cdot \cos \left[m\left(z-z_{0}\right)+\psi\right]$,

where $\psi$ is the wave phase for the reference level $z_{0}$. By substituting $T(z)$ from Eq. (7) into Eq. (6) and taking into account that $T(z) \approx T_{\mathrm{b}}(z)$, we have:

$$
\begin{aligned}
N^{2}(z) & =\frac{g}{T_{\mathrm{b}}(z)} \cdot\left(\frac{\partial T_{\mathrm{b}}(z)}{\partial z}+\frac{g}{c_{\mathrm{p}}}\right)+\frac{g m\left|T^{\prime}\right|}{T_{\mathrm{b}}(z)} \\
& \cdot \cos \left[m\left(z-z_{0}\right)+\psi+\pi / 2\right] .
\end{aligned}
$$

The first term in Eq. (8) is the simple background estimate of $N_{\mathrm{b}}^{2}=N_{\text {med }}^{2}$ and it may be used for substitution into Eq. (5) in 
order to determine $a_{\mathrm{e}}$. It is clear from Eq. (8) that the vertical profile $N_{\mathrm{b}}^{2}(z)$ can be calculated by application of Eq. (6) to the background profile $T_{\mathrm{b}}(z)$. The second term in Eq. (8) describes absolute fluctuations of $N^{2}$ associated with the temperature perturbations. It is easy to find from Eq. (8) that the amplitude $A_{N^{2}}^{\text {rel }}$ of relative fluctuations of the Brunt-Vaisala frequency squared $\left(N^{2}-N_{\mathrm{b}}^{2}\right) / N_{\mathrm{b}}^{2}$ is given by:

$A_{N^{2}}^{\mathrm{rel}}=a_{\mathrm{e}}=\frac{g|m|}{N_{\mathrm{b}}^{2}} \cdot \frac{\left|T^{\prime}\right|}{T_{\mathrm{b}}}=1-\frac{N_{\min }^{2}}{N_{\mathrm{b}}^{2}}$

where $N_{\min }^{2}=\min N^{2}$ is the local minimum of $N^{2}(z)$. Thus, the magnitude of relative amplitude threshold $a_{\mathrm{e}}$ may be expressed in terms of the temperature or $N^{2}$ and these two estimates of the wave amplitude $a_{\mathrm{e}}$ must be in mutual agreement. Note that the local shear instability and its associated turbulence in the Earth's stratosphere grow in the vertical shear of the transverse velocity component which maximizes at the local minimum of Brunt-Vaisala frequency (Fritts and Rastogi, 1985; Fritts, 1989; Dunkerton, 1989).

\section{Reconstruction of the IGW energy characteristics and wave fluxes}

With the determined wave parameters which were considered in the work of Gubenko et al. (2008) it is possible to reconstruct such important characteristics for IGW activity as the kinetic, potential and total wave energy, and also wave fluxes of the energy and horizontal momentum per unit mass. It is known that the total wave energy $E$ consists of two parts: kinetic, $E_{\mathrm{k}}$, and potential, $E_{\mathrm{p}}$, which are given by the following expressions (Gill, 1982):

$$
\begin{aligned}
E & =E_{\mathrm{k}}+E_{\mathrm{p}}=\frac{1}{2}\left|w^{\prime}\right|^{2}\left(1+\tan ^{2} \phi^{\prime}\right)=\frac{1}{2}\left(\left|w^{\prime}\right|^{2}+\left|u^{\prime}\right|^{2}\right), \\
E_{\mathrm{k}} & =\frac{1}{2}\left[\overline{u^{\prime 2}}+\overline{v^{\prime 2}}+\overline{w^{\prime 2}}\right]=\frac{1}{4}\left[\left|u^{\prime}\right|^{2}+\left|v^{\prime}\right|^{2}+\left|w^{\prime}\right|^{2}\right] \\
& =E \cdot \frac{1+(f / \omega)^{2} \sin ^{2} \phi^{\prime}}{2} \\
E_{\mathrm{p}} & =\frac{1}{2} \frac{g^{2}}{N^{2}} \overline{\left(\frac{T^{\prime}}{\bar{T}}\right)^{2}}=\frac{1}{4} \frac{g^{2}}{N^{2}}\left|\frac{T^{\prime}}{\bar{T}}\right|^{2}=E \cdot \frac{1-(f / \omega)^{2} \sin ^{2} \phi^{\prime}}{2} .
\end{aligned}
$$

Here and in the following, for simplicity, the tokens Re before primed quantities are omitted, and primed ones mean real perturbations to the background state; the overbar denotes a spatial average over a vertical wavelength $\lambda_{z}$; an angle $\phi^{\prime}$ is that between the wave vector direction and horizontal plane, and the following simple relation for $\phi^{\prime}$ holds:

$\tan \phi^{\prime}=\frac{|m|}{\left|k_{\mathrm{h}}\right|}=\frac{\lambda_{\mathrm{h}}}{\lambda_{\mathrm{z}}}$.

For IGWs with $\omega^{2}<<N^{2}$, Eqs. (10-12) can be easily obtained by using the dispersion and polarization Eqs. (1-4), with Eq. (13) and taking into account the fact that the average of some harmonic perturbation squared over a vertical wavelength is equal to the corresponding amplitude squared divided by 2 (for example, $\overline{u^{\prime 2}}=\left|u^{\prime}\right|^{2} / 2$ ). The ratio $p$ of the kinetic to potential energy may be found from Eqs. (11) and (12) with the aid of the dispersion Eq. (1):

$p=\frac{E_{\mathrm{k}}}{E_{\mathrm{p}}}=\frac{\omega^{2}+f^{2} \sin ^{2} \phi^{\prime}}{\omega^{2}-f^{2} \sin ^{2} \phi^{\prime}}=1+2 \frac{f^{2}}{N^{2}} \tan ^{2} \phi^{\prime}$.

The vertical,$\left|F_{\mathrm{z}}\right|$, and horizontal, $\left|F_{\mathrm{h}}\right|$, fluxes of wave energy per unit mass may be written as (Gill, 1982):

$\left|F_{\mathrm{z}}\right|=\left|C_{\mathrm{gz}}^{\mathrm{in}}\right| \cdot E$,

$\left|F_{\mathrm{h}}\right|=\left|C_{\mathrm{gh}}^{\mathrm{in}}\right| \cdot E$,

where $\left|C_{\mathrm{gz}}^{\text {in }}\right|$ and $\left|C_{\mathrm{gh}}^{\text {in }}\right|$ are the moduli of the intrinsic vertical and horizontal components of the group speed, correspondingly. By using the definitions of $\left|C_{\mathrm{gz}}^{\mathrm{in}}\right|$ and $\left|C_{\mathrm{gh}}^{\text {in }}\right|$, and the dispersion Eq. (1), one can find:

$$
\begin{aligned}
& \left|C_{\mathrm{gz}}^{\mathrm{in}}\right|=\left|\frac{\partial \omega}{\partial m}\right|=\left|C_{\mathrm{pz}}^{\mathrm{in}}\right| \cdot\left(1-\frac{f^{2}}{\omega^{2}}\right)=\frac{\left|k_{\mathrm{h}}\right| N}{m^{2}} \cdot \sqrt{1-\frac{f^{2}}{\omega^{2}}}, \\
& \left|C_{\mathrm{gh}}^{\mathrm{in}}\right|=\left|\frac{\partial \omega}{\partial k_{\mathrm{h}}}\right|=\left|C_{\mathrm{ph}}^{\mathrm{in}}\right| \cdot\left(1-\frac{f^{2}}{\omega^{2}}\right)=\frac{N}{|m|} \cdot \sqrt{1-\frac{f^{2}}{\omega^{2}}} .
\end{aligned}
$$

Taking into account the definition of the total vertical flux of horizontal momentum, $\left|F_{\mathrm{ph}}\right|$, due to IGW and the polarization Eqs. (2), (3), the following expression for $\left|F_{\mathrm{ph}}\right|$ can be found:

$$
\begin{aligned}
\left|F_{\mathrm{ph}}\right| & =\sqrt{\left(\overline{u^{\prime} \cdot w^{\prime}}\right)^{2}+\left(\overline{v^{\prime} \cdot w^{\prime}}\right)^{2}}=\left|\overline{u^{\prime} \cdot w^{\prime}}\right| \\
& =\frac{\left|u^{\prime}\right| \cdot\left|w^{\prime}\right|}{2}=\left|\frac{k_{\mathrm{h}}}{m}\right| \cdot \frac{\left|u^{\prime}\right|^{2}}{2} .
\end{aligned}
$$

\section{Validation of the developed technique and the experimental derivation of IGW parameters from RO temperature data}

Validation studies (Kitchen, 1989; Sofieva et al., 2008) indicate that separations of less than a few tens of kilometers and 1 or $2 \mathrm{~h}$ are necessary for useful comparisons between point measurement instruments. This implies that profiles should be almost exactly collocated in time and space for validation of high-resolution profiles. Radiosonde soundings consist of point measurements while RO soundings represent averages over finite volumes of the atmosphere and hence there are significant interpretation difficulties when the data obtained with the aid of two types of soundings are compared. To illustrate these difficulties, let us consider the example of comparison of temperature profiles from 
the COSMIC GPS RO and radiosonde launched at Kuching, Malaysia (see Fig. 3 in Tsuda et al., 2011). Tsuda et al. (2011) applied full spectrum inversion (FSI) up to $30 \mathrm{~km}$ altitude on COSMIC data and obtained the FSI-based temperature profiles in the lower stratosphere with the good temperature precision of $0.5 \mathrm{~K}$ and the increased vertical resolution of about 100-200 m, comparable to a ground-based radiosonde $(\sim 100 \mathrm{~m})$. Temperature profiles, given in Fig. 3 by Tsuda et al. (2011), correspond with two GPS RO events \#49 and $\# 50$ occurred within $400 \mathrm{~km}$ and $1 \mathrm{~h}$ from the balloon launch at Kuching. Note that indicated COSMIC GPS RO profiles satisfy the coincidence criterion for validation exercises (McDonald et al., 2010) which suggests that for horizontal separations below $500 \mathrm{~km}$ the majority of the variability (between $60 \%$ and $90 \%$ of the temperature variations) are likely to be associated with internal gravity waves. In the stratosphere, wavelike variations with the vertical wavelength of $>2 \mathrm{~km}$ are clearly seen in the RO temperature profiles shown in Fig. 3 by Tsuda et al. (2011). The generally good altitude correspondence between these wavelike structures both in the FSI and GO temperature retrievals for \#49 and \#50 GPS RO events is evident at $18-30 \mathrm{~km}$ interval. But examination of temperature changes in the radiosonde data (black line in Fig. 3 by Tsuda et al., 2011) shows a remarkably another pattern in which wavelike temperature variations with the vertical wavelength $>2 \mathrm{~km}$ are much smaller expressed in comparison with the RO temperature profiles. Since these comparisons use observations separated by distances smaller than marginally acceptable for RO validation exercises $(\sim 500 \mathrm{~km})$, then the above-mentioned discrepancy between the RO and radiosonde results compared may be due to different types of temperature soundings in the lower stratosphere.

Therefore, we suppose that the simultaneous highresolution radiosonde wind velocity and temperature data are most appropriate for the examination of the techniques. An additional advantage in the application of the simultaneous wind velocity and temperature data for examination of our analysis technique is the real possibility to estimate a wave amplitude threshold for shear instability and to find two independent estimates of actual wave amplitudes from vertical profiles of horizontal wind and temperature. In the case of IGW amplitude saturation which is a key approach for the correct application of our IGW reconstruction method to temperature data, these estimates of threshold and actual wave amplitudes must be in close mutual agreement (see below). Thus, the simultaneous wind velocity and temperature data may provide useful information for both the temperature data selection and the validation of the IGW saturation approach. For instance, Cot and Barat (1986) identified an inertia-gravity wave propagating upwards using a wind velocity hodograph analysis. In Table 1 (line 3 ) the wave parameters determined by Cot and Barat (1986) are shown. For the determination of IGW parameters from the basic dispersion and polarization relations they utilized not only the wind velocity data but temperature data also. Indeed, the horizontal wave-induced velocity amplitudes and ratio $f / \omega$ were obtained by using a wind velocity hodograph analysis. Such characteristics of the wave as the horizontal wavelength and intrinsic vertical and horizontal phase speeds were obtained with the aid of the dispersion and polarization relations and the background value of $N$, estimated from the radiosonde temperature data.

For experimental verification of the analysis technique proposed, we used the results of the simultaneous temperature and wind velocity measurements obtained in a highresolution balloon experiment (Cot and Barat, 1986), where a nearly monochromatic and long-period wave propagating upward in the stratosphere was identified. By using the temperature data only, we independently identified the same wave and reconstructed the ratio $f / \omega$ and other wave parameters. We calculated the magnitude of $a_{\mathrm{e}}$ from the temperature measurements and tested the analyzed temperature variations with the aid of the IGW identification criterion. We found that the magnitude $a_{\mathrm{e}}=0.67<1$ satisfies the IGW identification criterion (see Table 1, line 5) and concluded that the wavelike temperature variations in the radiosonde data can be considered as wave-induced. Relative deviations of determined and reconstructed wave parameters are shown on line 7 of Table 1. A comparison of the determined and reconstructed wave parameters shows a good agreement between them. It is seen from the values given in Table 1 that the relative deviations of the reconstructed parameters are not larger than $31 \%$. The best agreement is found for such parameters as $f / \omega, \omega,\left|C_{\mathrm{pz}}^{\text {in }}\right|,\left|w^{\prime}\right|$ which are reproduced with relative deviations $<10 \%$. In order to give the experimental evidence for the IGW saturation, we calculated the relative amplitude threshold for shear instability using the value $f / \omega=0.8$, determined by Cot and Barat (1986) from the wind velocity data (Table 1, line 3). Substituting the value $f / \omega=0.8$ into Eq. (7) of Gubenko et al. (2008) gives the estimate of the threshold wave amplitude $a=0.75$ which is close to the estimate of the actual wave amplitude $a_{\mathrm{e}}=0.67$ found from the temperature data (Table 1, line 5). The second independent estimate of the actual wave amplitude $a_{\mathrm{u}}=\left|u^{\prime}\right| /\left|C_{\mathrm{ph}}^{\text {in }}\right| \simeq 0.63$ can be found in an alternative manner by using the wave parameters $\left|u^{\prime}\right|=3.3 \mathrm{~m} \mathrm{~s}^{-1}$ and $\left|C_{\mathrm{ph}}^{\mathrm{in}}\right|=5.2 \mathrm{~m} \mathrm{~s}^{-1}$ determined by Cot and Barat (1986) (see Table 1, line 3). Introducing the ratio $d$ of the actual to threshold wave amplitude as a measure of the wave saturation degree, one can find that in the present case study we have close independent estimates $d_{\mathrm{e}}=0.89$ and $d_{\mathrm{u}}=0.85$ of the wave saturation degree derived from the temperature and wind velocity data, correspondingly. Mutual agreement between these estimates demonstrates the high degree ( $85 \%-89 \%)$ of the wave amplitude saturation and provides the experimental evidence of the IGW saturation approach. 
Table 1. Wave parameters determined by Cot and Barat (1986) using a wind speed hodograph analysis and those reconstructed from temperature data. Relative deviations between determined and reconstructed wave parameters are indicated.

\begin{tabular}{|c|c|c|c|c|c|c|c|c|c|c|c|}
\hline $\begin{array}{l}\lambda_{z} \\
\mathrm{~km}\end{array}$ & $\left|T^{\prime}\right|, \mathrm{K}$ & $\bar{T}, \mathrm{~K}$ & $\begin{array}{r}N \\
\operatorname{rads}^{-1}\end{array}$ & $a_{\mathrm{e}}$ & $f / \omega$ & $\begin{array}{l}\omega \cdot 10^{4} \\
\mathrm{rad} \mathrm{s}^{-1}\end{array}$ & 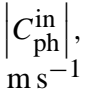 & $\begin{array}{r}|u| \mid \\
\mathrm{ms}^{-1}\end{array}$ & $\begin{array}{l}\lambda_{\mathrm{h}}, \\
\mathrm{km}\end{array}$ & $\begin{array}{l}\left|C_{\mathrm{pz}}^{\mathrm{in}}\right|, \\
\mathrm{m} \mathrm{s}^{-1}\end{array}$ & $\begin{array}{r}|w \prime|, \\
\mathrm{ms}^{-1}\end{array}$ \\
\hline \multicolumn{12}{|c|}{ Wave parameters determined by Cot and Barat (1986) } \\
\hline 1.0 & 1.0 & 231.5 & 0.02 & - & 0.80 & 1.25 & 5.2 & 3.3 & 260 & 0.020 & 0.013 \\
\hline \multicolumn{4}{|c|}{ Basic parameters for reconstruction } & \multicolumn{8}{|c|}{ Parameters reconstructed from temperature data } \\
\hline \multirow[t]{3}{*}{1.0} & 1.0 & 231.5 & 0.02 & 0.67 & 0.86 & 1.16 & 6.3 & 4.2 & 341 & 0.018 & 0.012 \\
\hline & & & & \multicolumn{8}{|c|}{ Relative deviations (\%) of determined and reconstructed wave parameters } \\
\hline & & & & - & 7.5 & 7.2 & 21.2 & 27.3 & 31.2 & 10.0 & 7.7 \\
\hline
\end{tabular}

In order to demonstrate the practical application of the proposed technique, we used temperature data obtained from CHAMP and COSMIC GPS radio occultations where wavelike periodic structures in the lower stratosphere were visible. The altitude sampling of the four raw profiles is unequal, and for providing equidistant altitude steps required for the analysis, the data were smoothed by a sliding average over the 200-m interval and linearly interpolated to a regular $100-\mathrm{m}$ grid. The altitude intervals $L$ of wave observations were restricted by stratospheric levels from 15 to $36 \mathrm{~km}$ where the RO temperature data have the high vertical resolution $\delta h$ and accuracy $\delta T$. It is known that below $30 \mathrm{~km}$ within the upper troposphere and lower stratosphere, the influence of the ionosphere error is negligible and the temperature error is less than $1 \mathrm{~K}$ and vertical resolution is better than $1 \mathrm{~km}$ (Hocke, 1997; Steiner and Kirchengast, 2000). Gobiet et al. (2007) found that the CHAMP temperature accuracy is better than $0.5 \mathrm{~K}$ between 10 and $30 \mathrm{~km}$. Scherllin-Pirscher et al. (2011) found very good agreement between data characteristics of different missions. In the global mean, observational errors agree within $0.2 \mathrm{~K}$ in dry temperature at altitude levels between 4 and $35 \mathrm{~km}$. In the case of measurement temperature errors, we have, instead of the theoretical IGW criterion, the modified criterion for the experimental magnitude $a_{\mathrm{e}}$, namely (Gubenko et al., 2008, 2011):

$1>(1+X) a_{\mathrm{e}}>a_{\mathrm{e}}>(1-X) a_{\mathrm{e}}>0$

where $X=\left|\delta a_{\mathrm{e}} / a_{\mathrm{e}}\right|$ is the relative uncertainty in the amplitude threshold $a_{\mathrm{e}}$ of the temperature wave field and $\delta a_{\mathrm{e}}$ is the standard deviation. The expression (Eq. 20) states that not only $a_{\mathrm{e}}$, but also $\left(a_{\mathrm{e}}-\delta a_{\mathrm{e}}\right)$ and $\left(a_{\mathrm{e}}+\delta a_{\mathrm{e}}\right)$ satisfy the theoretical IGW criterion. This implies that we have reliable estimates of wave parameters because the relative uncertainties and standard deviations of reconstructed IGW parameters are limited in this case. The detailed discussion of errors for the estimated wave parameters and analytical expressions for their determination from the real measurement uncertainties $\delta T$ and $\delta h$ can be found in the work of Gubenko et al. (2008).
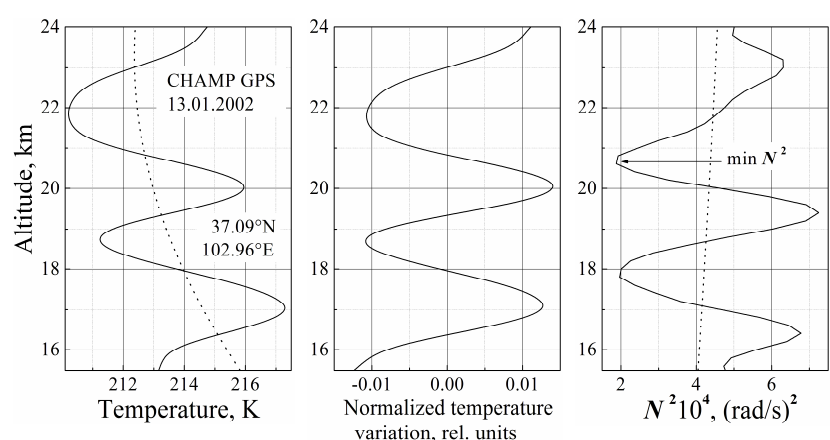

Fig. 1. Wavelike temperature oscillations in the middle latitudes of the Earth's atmosphere observed from the vertical temperature profile retrieved from the CHAMP GPS radio occultation on 13 January 2002. In successive panels (from left to right), the vertical profiles of temperature (left panel), normalized temperature variation (middle panel), and Brunt-Vaisala frequency squared $N^{2}$ (right panel) are plotted. The solid lines are the raw data and dotted lines represent the corresponding background data. The vertical background profile was determined from the raw data by a least-squares cubic polynomial curve fit within the altitude interval of wave observations. The coordinates of sounded region and date of observation are indicated.

Let us consider the CHAMP GPS radio occultation retrievals of temperature profiles in the Earth's stratosphere. Figure 1 shows the example of IGW observations in the middle latitudes at altitudes from 15.5 to $24 \mathrm{~km}$. The RO measurements were made on 13 January 2002 in the atmosphere over the region with the latitude $37.09^{\circ} \mathrm{N}$ and longitude $102.96^{\circ} \mathrm{E}$. In successive panels of Fig. 1, from left to right, are plotted the altitude RO profiles of temperature, normalized temperature variation, and Brunt-Vaisala frequency squared $N^{2}$. The solid line (left panel) is the raw temperature data, $T$, and the dotted line is the background temperature profile, $T_{\mathrm{b}}$, determined by a least-squares cubic polynomial curve fit within the altitude interval $L=8.5 \mathrm{~km}$ of 

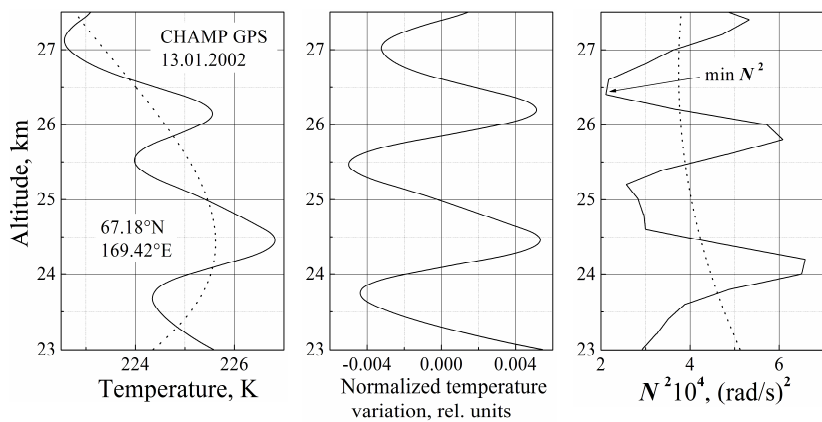

Fig. 2. The same as Fig. 1, except from radio occultation conducted in the high latitudes of the Earth's atmosphere on 13 January 2002.

wave observations. Based on these raw and background profiles, we computed the corresponding raw, $N^{2}$, (solid line) and mean, $N_{\mathrm{b}}^{2}$, (dotted line) profiles of the Brunt-Vaisala frequency squared (right panel) with the aid of Eq. (6). In order to compute the normalized temperature variation profile $\left(T^{\prime} / T_{\mathrm{b}}\right)$, the standard expression $T^{\prime} / T_{\mathrm{b}}=\left(T-T_{\mathrm{b}}\right) / T_{\mathrm{b}}$ was used. The altitude profile $T^{\prime}(z) / T_{\mathrm{b}}(z)$ (middle panel ) was used for evaluation of the normalized temperature perturbation amplitude $|\widehat{T}|=\left|T^{\prime}\right| / T_{\mathrm{b}}$ and vertical wavelength $\lambda_{\mathrm{z}}$. It was found that the value of the normalized amplitude is equal to $10^{-2}$ and the vertical wavelength is equal to $3.2 \mathrm{~km}$. For the calculation of the experimental magnitude of the relative amplitude threshold $a_{\mathrm{e}}$ it is necessary to ensure a good estimate of the Brunt-Vaisala frequency squared. Figure 1 shows plots of $N^{2}$ and $N_{\mathrm{b}}^{2}$ profiles (right panel) for the sounded region and it is seen from Fig. 1 that the $N_{\mathrm{b}}^{2}$ value is weakly sensitive to actual thermal structure and well represented by a constant for the investigated altitude range. For the determination of the experimental value $a_{\mathrm{e}}$, we thus took the constant value $N_{\mathrm{b}}^{2}=4.35 \cdot 10^{-4} \mathrm{rad}^{2} \mathrm{~s}^{-2}$. The local minimum of the Brunt-Vaisala frequency squared $N_{\min }^{2}=\min N^{2} \approx 2 \cdot 10^{-4} \mathrm{rad}^{2} \mathrm{~s}^{-2}$ is shown in Fig. 1 by the arrow. It was discussed above that the local shear instability and its associated turbulence grow at the local minimum of Brunt-Vaisala frequency (Fritts and Rastogi, 1985; Fritts, 1989; Dunkerton, 1989). Cot and Barat (1986) concluded that the thin turbulent layers cannot perturb the wave field structure and must have (1) a thickness substantially smaller than $\lambda_{z}$; (2) a horizontal extension of the order $\lambda_{\mathrm{h}}$; and (3) a vertical propagation with velocity $\left|C_{\mathrm{pz}}^{\text {in }}\right|$.

The magnitude of relative amplitude threshold $A_{N^{2}}^{\text {rel }}=$ 0.54 , expressed in terms of $N^{2}$ may be obtained from Eq. (9) using estimates of $N_{\min }^{2}$ and $N_{\mathrm{b}}^{2}$. Substituting the values of $N_{\mathrm{b}}^{2}, \lambda_{z}$ and $\left|T^{\prime}\right| / T_{\mathrm{b}}$ into Eq. (5), it was found that $a_{\mathrm{e}}=0.44$. In order to find uncertainties for estimated IGW parameters, we assumed that the initial temperature data were obtained with the accuracy $\delta T=0.5 \mathrm{~K}$ and vertical resolution $\delta h=1200 \mathrm{~m}$ (Gobiet et al., 2007; Scherllin-Pirscher et al.,
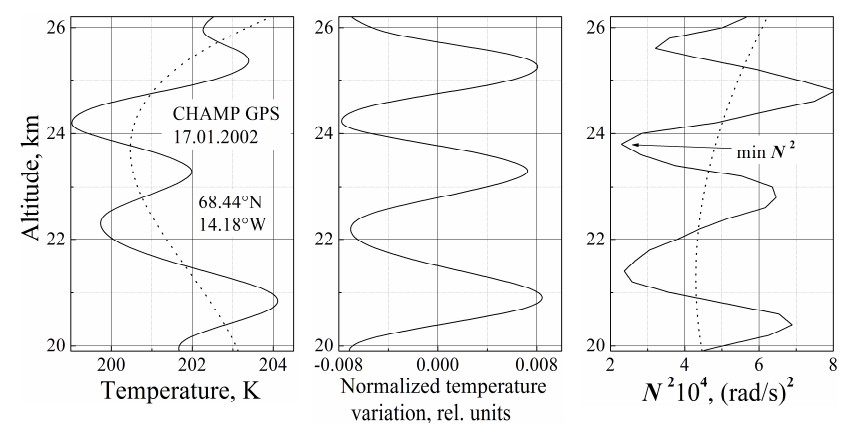

Fig. 3. The same as Fig. 1, except from radio occultation made in the high latitudes of the Earth's atmosphere on 17 January 2002.
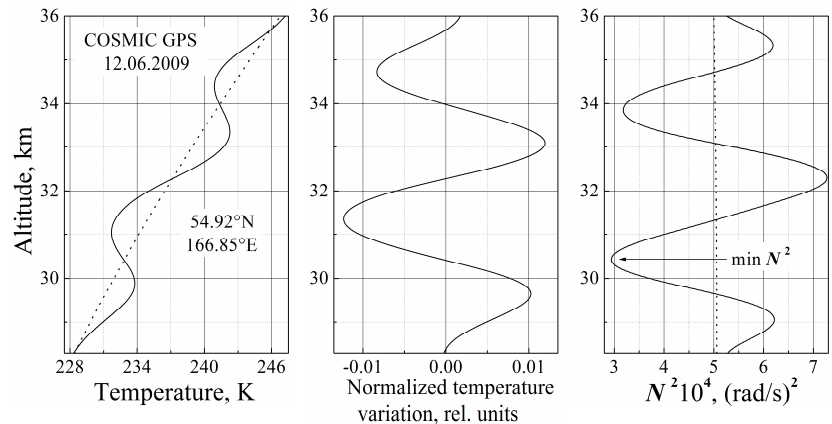

Fig. 4. Wavelike temperature oscillations in the middle latitudes of the Earth's atmosphere observed from the vertical temperature profile retrieved from the COSMIC GPS radio occultation on 12 June 2009. Description of panels is the same as in Fig. 1.

2011). Following Gubenko et al. (2008), we have found that the relative uncertainty of $a_{\mathrm{e}}$ is equal to $X=0.32$, and values $a_{\mathrm{e}}=0.44$ and $A_{N^{2}}^{\mathrm{rel}}=0.54$ satisfy the modified criterion (Eq. 20). A small disagreement between two estimates of the wave amplitude may be caused by the different power spectra of the temperature and $N^{2}$ fluctuations. Thus, the strong wavelike oscillations of $T$ and $N^{2}$ are probably caused by an internal gravity wave (see IGW parameters and their uncertainties in Table 2).

Figure 2 demonstrates the example of IGW observations in the high latitudes at altitudes from 23.0 to $27.5 \mathrm{~km}$. The CHAMP GPS RO measurements were conducted on 13 January 2002 in the atmospheric region with the latitude $67.18^{\circ} \mathrm{N}$ and longitude $169.42^{\circ} \mathrm{E}$. Figure 3 shows the example of IGW observations in the high latitudes at altitudes from 19.9 to $26.2 \mathrm{~km}$. The CHAMP GPS RO measurements were conducted on 17 January 2002 in the atmospheric region with the latitude $68.44^{\circ} \mathrm{N}$ and longitude $14.18^{\circ} \mathrm{W}$. Figure 4 demonstrates the example of IGW observations in the middle latitudes at altitudes from 28.3 to $36.0 \mathrm{~km}$. These COSMIC GPS RO measurements were made on 12 June 2009 in the atmospheric region with the latitude $54.92^{\circ} \mathrm{N}$ and longitude $166.85^{\circ}$ E. Descriptions in Figs. 2-4 are the same as in Fig. 1. 
Table 2. Wave parameters found from CHAMP \& COSMIC GPS radio occultation retrievals of temperature profiles in four regions of the Earth's atmosphere. The coordinates of sounded regions, time and altitude intervals of observations are indicated. Uncertainties of determined parameters are also shown when they are less than $100 \%$.

\begin{tabular}{|c|c|c|c|c|}
\hline Satellite & CHAMP & CHAMP & CHAMP & COSMIC \\
\hline \multirow{5}{*}{$\begin{array}{r}\text { IGW } \\
\text { parameters }\end{array}$} & 13 January 2002 & 13 January 2002 & 17 January 2002 & 12 June 2009 \\
\hline & 06:03 UT & 15:37 UT & $15: 27 \mathrm{UT}$ & 23:17 UT \\
\hline & $37.09^{\circ} \mathrm{N}$ & $67.18^{\circ} \mathrm{N}$ & $68.44^{\circ} \mathrm{N}$ & $54.92^{\circ} \mathrm{N}$ \\
\hline & $102.96^{\circ} \mathrm{E}$ & $169.42^{\circ} \mathrm{E}$ & $14.18^{\circ} \mathrm{W}$ & $166.85^{\circ} \mathrm{E}$ \\
\hline & {$[15.5 \div 24.0] \mathrm{km}$} & {$[23.0 \div 27.5] \mathrm{km}$} & {$[19.9 \div 26.2] \mathrm{km}$} & {$[28.3 \div 36.0] \mathrm{km}$} \\
\hline$L, \mathrm{~km}$ & 8.5 & 4.5 & 6.3 & 7.7 \\
\hline$\lambda_{\mathrm{z}}, \mathrm{km}$ & $3.2 \pm 0.7$ & $1.7 \pm 0.7$ & $2.1 \pm 0.7$ & $3.4 \pm 0.8$ \\
\hline$|\widehat{T}|, 10^{-3}$ rel. units & $10.0 \pm 1.4$ & $4.9 \pm 1.4$ & $7.8 \pm 1.4$ & $12.5 \pm 1.4$ \\
\hline$N_{\mathrm{b}}^{2}, 10^{-4} \mathrm{rad}^{2} \mathrm{~s}^{-2}$ & $4.35 \pm 0.64$ & $3.75 \pm 0.80$ & $4.50 \pm 0.96$ & $5.00 \pm 0.55$ \\
\hline$a_{\mathrm{e}}$, rel. units & $0.44 \pm 0.14$ & $0.48 \pm 0.27$ & $0.50 \pm 0.22$ & $0.45 \pm 0.13$ \\
\hline$f / \omega$, rel. units & $0.96 \pm 0.03$ & $0.95 \pm 0.08$ & $0.94 \pm 0.07$ & $0.96 \pm 0.03$ \\
\hline$\omega, 10^{-4} \mathrm{rad} \mathrm{s}^{-1}$ & $0.92 \pm 0.03$ & $1.42 \pm 0.12$ & $1.44 \pm 0.11$ & $1.25 \pm 0.04$ \\
\hline$T^{\text {in }}$, hours & $19.0 \pm 0.7$ & $12.3 \pm 1.0$ & $12.1 \pm 0.9$ & $14.0 \pm 0.5$ \\
\hline $\tan \phi^{\prime}$, rel. units & $800 \pm 436$ & 434 & $437 \pm 353$ & $611 \pm 319$ \\
\hline $90^{\circ}-\phi^{\prime}, \operatorname{deg}$ & $0.07 \pm 0.04$ & 0.13 & $0.13 \pm 0.11$ & $0.09 \pm 0.05$ \\
\hline$\left|C_{\mathrm{ph}}^{\mathrm{in}}\right|, \mathrm{ms}^{-1}$ & $37.4 \pm 17.3$ & $16.4 \pm 14.2$ & $21.2 \pm 14.3$ & $41.3 \pm 18.1$ \\
\hline$\left|u^{\prime}\right|, \mathrm{m} \mathrm{s}^{-1}$ & $16.5 \pm 4.2$ & $7.9 \pm 3.8$ & $10.7 \pm 4.0$ & $18.7 \pm 4.8$ \\
\hline$\left|v^{\prime}\right|, \mathrm{ms}^{-1}$ & $15.9 \pm 4.3$ & $7.5 \pm 3.9$ & $10.1 \pm 4.1$ & $17.9 \pm 4.8$ \\
\hline$\left|C_{\mathrm{pz}}^{\mathrm{in}}\right|, 10^{-3} \mathrm{~m} \mathrm{~s}^{-1}$ & $46.7 \pm 10.9$ & $37.8 \pm 16.8$ & $48.6 \pm 16.4$ & $67.5 \pm 16.0$ \\
\hline$\left|w^{\prime}\right|, 10^{-3} \mathrm{~ms} \mathrm{~s}^{-1}$ & $20.7 \pm 8.6$ & $18.1 \pm 14.0$ & $24.5 \pm 14.8$ & $30.6 \pm 12.1$ \\
\hline$\lambda_{\mathrm{h}}, \mathrm{km}$ & $2560 \pm 1260$ & $727 \pm 680$ & $927 \pm 684$ & $2080 \pm 970$ \\
\hline$\left|C_{\mathrm{gh}}^{\mathrm{in}}\right|, \mathrm{m} \mathrm{s}^{-1}$ & $3.0 \pm 1.4$ & $1.6 \pm 1.4$ & $2.4 \pm 1.6$ & $3.6 \pm 1.6$ \\
\hline$\left|C_{\mathrm{gz}}^{\mathrm{in}}\right|, 10^{-3} \mathrm{~m} \mathrm{~s}^{-1}$ & $3.8 \pm 2.7$ & 3.7 & 5.5 & $5.8 \pm 3.9$ \\
\hline$E_{\mathrm{p}}, \mathrm{m}^{2} \mathrm{~s}^{-2}$ & $5.5 \pm 1.8$ & $1.5 \pm 0.9$ & $3.3 \pm 1.4$ & $7.5 \pm 1.9$ \\
\hline$E, \mathrm{~m}^{2} \mathrm{~s}^{-2}$ & $137 \pm 70$ & $30.8 \pm 29.8$ & $57.3 \pm 43.0$ & $175 \pm 89$ \\
\hline$p=E_{\mathrm{k}} / E_{\mathrm{p}}$, rel. units & $23.7 \pm 15.0$ & 19.2 & $16.6 \pm 15.2$ & $22.3 \pm 13.2$ \\
\hline$\left|F_{\mathrm{h}}\right|, \mathrm{m}^{3} \mathrm{~s}^{-3}$ & $413 \pm 286$ & 50 & 138 & $621 \pm 417$ \\
\hline$\left|F_{\mathrm{z}}\right|, \mathrm{m}^{3} \mathrm{~s}^{-3}$ & $0.52 \pm 0.46$ & 0.12 & 0.32 & $1.02 \pm 0.86$ \\
\hline$\left|F_{\mathrm{ph}}\right|, \mathrm{m}^{2} \mathrm{~s}^{-2}$ & $0.17 \pm 0.08$ & $0.07 \pm 0.06$ & $0.13 \pm 0.09$ & $0.29 \pm 0.13$ \\
\hline
\end{tabular}

From the temperature data, we compute the wave parameters for the four sounded regions. In Table 2 we have summarized all the wave parameters and their uncertainties when they are less than $100 \%$. Thus we have shown that the wave characteristics can be obtained from a single temperature profile in the case of positive IGW identification.

In present paper we have extended the analysis technique of Gubenko et al. (2008) in order to reconstruct the complete set of IGW characteristics (including such important parameters as the kinetic and potential wave energy and IGW fluxes of the energy and horizontal momentum) from temperature perturbations in a single vertical profile. Observations of individual IGW events such as those considered here and simultaneous estimates of wave parameters can be used for parameterizations of internal gravity waves in general circulation models. We have demonstrated that the inspection of the simultaneous wind velocity and temperature data may provide useful information for the examination and validation of an IGW saturation approach that is the important point for the correct application of our IGW reconstruction method to temperature data. We have also proposed here an alternative analysis method to estimate the relative amplitude threshold (and to extract IGW parameters) from perturbations of the Brunt-Vaisala frequency squared in a single vertical profile.

\section{Conclusions}

A new method for the determination of IGW parameters from a single vertical temperature or density profile measurement in a planetary atmosphere has been developed. This method does not require any additional information not contained in 
the profile and may be used for the analysis of profiles measured by various techniques.

The criterion for the IGW identification has been formulated and argued. In the case when this criterion is satisfied then analyzed temperature or density fluctuations can be considered as wave-induced.

The experimental verification of the analysis technique proposed was made by using the results of simultaneous temperature and wind velocity measurements obtained in a highresolution balloon experiment (Cot and Barat, 1986), where a nearly monochromatic and long-period wave propagating upward in the stratosphere was identified. Using the temperature data only, we reconstructed all wave parameters with relative deviations not larger than $30 \%$.

The suggested method is most effective in the case of low intrinsic IGW frequencies when the experimentally determined amplitude threshold $a_{\mathrm{e}}$ appreciably differs from unity.

The analysis of radio occultation data on the basis of this proposed method gave the possibility to identify the IGWs in the Earth's atmosphere and to determine the magnitudes of key wave parameters such as the intrinsic frequency, amplitudes of vertical and horizontal perturbations of the wind velocity, vertical and horizontal wavelengths, intrinsic vertical and horizontal phase (and group) speeds, kinetic and potential energy, vertical fluxes of the wave energy and horizontal momentum.

Acknowledgements. This work was partially supported by the RFBR Grant (No. 10-02-01015- $a$ ) of the Russian Academy of Sciences.

Edited by: U. Foelsche

\section{References}

Alexander, M. J. and Rosenlof, K. H.: Nonstationary gravity wave forcing of the stratospheric zonal mean wind, J. Geophys. Res., 101, 23465-23474, 1996.

Cot, C. and Barat, J. : Wave-turbulence interaction in the stratosphere: A case study, J. Geophys. Res., 91, 2749-2756, 1986.

Dunkerton, T. J.: Theory of internal gravity wave saturation , Pure Appl. Geophys., 130, 373-397, 1989.

Dunkerton, T. J.: Role of gravity waves in the quasi-biennial oscillation, J. Geophys. Res., 102, 26053-26076, 1997.

Ern, M., Preusse, P., Alexander, M. J., and Warner, C. D.: Absolute values of gravity wave momentum flux derived from satellite data, J. Geophys. Res., 109, D20103, doi:10.1029/2004JD004752, 2004.

Fetzer, E. J. and Gille, J. C.: Gravity wave variances in LIMS temperatures, I, Variability and comparison with background winds, J. Atmos. Sci., 51, 2461-2483, 1994.

Fritts, D. C.: A review of gravity wave saturation processes, effects, and variability in the middle atmosphere, Pure Appl. Geophys., 130, 343-371, 1989.

Fritts, D. C. and Alexander, M. J.: Gravity wave dynamics and effects in the middle atmosphere, Rev. Geophys., 41, 1-64, 1003, doi:10.1029/2001RG000106, 2003.
Fritts, D. C. and Rastogi, P. K.: Convective and dynamical instabilities due to gravity motions in the lower and middle atmosphere: Theory and observations, Radio Sci., 20, 1247-1277, 1985.

Garcia, R. R. and Sassi, F.: Modulation of the mesospheric semiannual oscillation by the quasibiennial oscillation, Earth Planet. Space, 51, 563-569, 1999.

Gill, A. E.: Atmosphere-ocean dynamics, Academic Press, New York, London, Paris, San Diego, San Francisco, San Paulo, Sidney, Tokyo, Toronto, 1982.

Giorgetta, M. A., Manzini, E., and Roeckner, E.: Forcing of the quasi-biennial oscillation from a broad spectrum of atmospheric waves, Geophys. Res. Lett., 29, 1245, doi:10.1029/2002GL014756, 2002.

Gobiet, A., Kirchengast, G., Manney, G. L., Borsche, M., Retscher, C., and Stiller, G.: Retrieval of temperature profiles from CHAMP for climate monitoring: intercomparison with Envisat MIPAS and GOMOS and different atmospheric analyses, Atmos. Chem. Phys., 7, 3519-3536, doi:10.5194/acp-7-3519-2007, 2007.

Gubenko, V. N., Pavelyev, A. G., and Andreev, V. E.: Determination of the intrinsic frequency and other wave parameters from a single vertical temperature or density profile measurement, J. Geophys. Res., 113, D08109, doi:10.1029/2007JD008920, 2008.

Gubenko, V. N., Pavelyev, A. G., Salimzyanov, R. R., and Andreev, V. E.: Method of the determination of internal gravity wave parameters from a vertical temperature or density profile measurement in the Earth's atmosphere, Cosmic Res., 49, accepted, 2011.

Hines, C. O.: Doppler-spread parameterization of gravity-wave momentum deposition in the middle atmosphere. Part 1: Basic formulation, J. Atmos. Sol.-Terr. Phy., 59, 371-386, 1997.

Hocke, K.: Inversion of GPS meteorology data, Ann. Geophys., 15, 443-450, doi:10.1007/s00585-997-0443-1, 1997.

Kitchen, M.: Representativeness errors for radiosonde observations, Q. J. Roy. Meteorol. Soc., 115, 673-700, 1989.

Lindzen, R. S.: Turbulence and stress owing to gravity wave and tidal breakdown, J. Geophys. Res., 86, 9707-9714, 1981.

Liou, Y. A., Pavelyev, A. G., Huang, C. Y., Igarashi, K., Hocke, K., and Yan, S. K.: Analytic method for observation of the gravity waves using radio occultation data, Geophys. Res. Lett., 30, 20, doi:10.1029/2003GL017818, 2003.

Liou, Y. A., Pavelyev, A. G., Wickert, J., Huang, C. Y., Yan, S. K., and Liu, S. F.: Response of GPS occultation signals to atmospheric gravity waves and retrieval of gravity wave parameters, GPS Solutions, 8, 103-111, 2004.

Matsuno, T.: A quasi one-dimensional model of the middle atmosphere circulation interacting with internal gravity-waves, J. Meteorol. Soc. Jpn., 60, 215-226, 1982.

Mayr, H. G., Mengel, J. G., Hines, C. O., Chan, K. L., Arnold, N. F., Reddy, C.A., and Porter, H. S.: The gravity wave Doppler spread theory applied in a numerical spectral model of the middle atmosphere, 2. Equatorial oscillations, J. Geophys. Res., 102, 26093-26105, 1997.

Mayr, H. G., Mengel, J. G., and Chan, K. L.: Equatorial oscillations maintained by gravity waves as described with the Doppler spread parameterization: 1. Numerical experiments, J. Atmos. Sol.-Terr. Phy., 60, 181-199, 1998.

McDonald, A. J.,Tan, B., and Chu, X.: Role of gravity waves in the spatial and temporal variability of stratospheric temperature measured by COSMIC/FORMOSAT-3 and 
Rayleigh lidar observations, J. Geophys. Res., 115, D19128, doi:10.1029/2009JD013658, 2010.

McLandress, C., Alexander, M. J., and Wu, D. L.: Microwave Limb Sounder observations of gravity waves in the stratosphere: A climatology and interpretation, J. Geophys. Res., 105, 1194711967, 2000.

Medvedev, A. S. and Klaassen, G. P.: Parameterization of gravity wave momentum deposition based on nonlinear wave interactions: Basic formulation and sensitivity tests, J. Atmos. Sol.-Terr. Phy., 62, 1015-1033, 2000.

Preusse, P., Schaeler, B., Bacmeister, J. T., and Offermann, D.: Evidence for gravity waves in CRISTA temperatures, Adv. Space Res., 24, 1601-1604, 1999.

Preusse, P., Eckermann, S. D., and Offermann, D.: Comparison of global distribution of zonal-mean gravity wave variance inferred from different satellite measurements, Geophys. Res. Lett., 27, 3877-3880, 2000.

Preusse, P., Dombrack, A., Eckermann, S. D., Riese, M., Schaeler, B., Bacmeister, J. T., Broutman, D., and Grossmann, K. U.: Space-based measurements of stratospheric mountain waves by CRISTA: I. Sensitivity, analysis method, and a case study, J. Geophys. Res., 107, 8178, doi:10.1029/2001JD000699, 2002.

Sato, K. : A statistical study of the structure, saturation and sources of inertio-gravity waves in the lower stratosphere observed with the MU radar, J. Atmos. Sol.-Terr. Phy., 56, 755-774, 1994.

Sato, K. and Dunkerton, T. J.: Estimates of momentum flux associated with equatorial Kelvin and gravity waves, J. Geophys. Res., 102, 26247-26261, 1997.

Scaife, A. A., Butchart, N., Warner, C. D., Stainforth, D., Norton, W., and Austin, J.: Realistic quasi-biennial oscillations in a simulation of the global climate, Geophys. Res. Lett., 27, 3481-3484, 2000.

Scherllin-Pirscher, B., Steiner, A. K., Kirchengast, G., Kuo, Y.-H., and Foelsche, U.: Empirical analysis and modeling of errors of atmospheric profiles from GPS radio occultation, Atmos. Meas. Tech., 4, 1875-1890, doi:10.5194/amt-4-1875-2011, 2011.

Sofieva, V. F., Dalaudier, F., Kivi, R., and Kyro, E.: On the variability of temperature profiles in the stratosphere: Implications for validation, Geophys. Res. Lett., 35, L23808, doi.:10.1029/2008GL035539, 2008.
Steiner, A. K. and Kirchengast, G.: GW spectra from GPS/MET occultation observations, J. Atmos. Ocean. Tech., 17, 495-503, 2000 .

Tanaka, H. and Yamanaka, M. D.: Atmospheric circulation in the lower stratosphere induced by the mesoscale mountain wave breakdown, J. Meteorol. Soc. Jpn., 63, 1047-1054, 1985.

Tsuda, T. and Hocke, K.: Vertical wave number spectrum of temperature fluctuations in the stratosphere using GPS occultation data, J. Meteorol. Soc. Jpn., 80, 1-13, 2002.

Tsuda, T., Murayama, Y., Yamamoto, M., Kato, S., and Fukao, S.: Seasonal variation of momentum flux in the mesosphere observed with the MU radar, Geophys. Res. Lett., 6, 725-728, 1990.

Tsuda, T., Nishida, M., Rocken, C., and Ware, R. H.: A global morphology of GW activity in the stratosphere revealed by the GPS occultation data (GPS/MET), J. Geophys. Res., 105, 7257 7273, 2000.

Tsuda, T., Lin, X., Hayashi, H., and Noersomadi: Analysis of vertical wave number spectrum of atmospheric gravity waves in the stratosphere using COSMIC GPS radio occultation data, Atmos. Meas. Tech., 4, 1627-1636, doi:10.5194/amt-4-1627-2011, 2011.

Wang, L. and Alexander, M. J.: Global estimates of gravity wave parameters from GPS radio occultation temperature data, J. Geophys. Res., 115, D21122, doi:10.1029/2010JD013860, 2010.

Warner, C. D. and McIntyre, M. E.: Toward an ultra-simple spectral gravity wave parameterization for general circulation models, Earth Planet. Space, 51, 475-484, 1999.

Wu, D. L. and Waters, J. W.: Gravity-wave-scale temperature fluctuations seen by the UARS MLS, Geophys. Res. Lett., 23, 32893292, 1996a.

Wu, D. L.: Horizontal wavenumber spectra of MLS radiance fluctuations, J. Atmos. Sol.-Terr. Phy., 63, 1465-1477, 2001.

Wu, D. L. and Waters, J. W.: Satellite observations of atmospheric variances: A possible indication of gravity waves, Geophys. Res. Lett., 23, 3631-3634, 1996b. 